\title{
Intoxicación alcohólica aguda
}

\author{
IZOUIERDO, M.
}

Unidad de Alcoholismo. Hospital Psiquiátrico. Plasencia. Cáceres

Enviar correspondencia a: Mercedes Izquierdo Serrano. Unidad de Alcoholismo. Hospital Psiquiátrico. 10600 Plasencia (Cáceres). E-mail: meriza@terra.es

\section{RESUMEN}

La Intoxicación Etílica Aguda (IEA) es el trastorno orgánico más común inducido por alcohol y la intoxicación aguda más frecuente en nuestro medio. Afecta al $1,1 \%$ de la población, sobre todo varones entre 19-28 años. La dosis letal 50 es 5 gr./l con ingesta aproximada de alcohol de $3 \mathrm{gr} / \mathrm{Kg}$. peso. La mortalidad por coma etílico es del $5 \%$.

En la IEA el riesgo de sufrir TCE y Hematoma Subdural es más del doble y está aumentado el de convulsiones, intentos autolíticos e intoxicaciones combinadas.

La Resaca es más prevalente en bebedores de consumo bajo y moderado de Alcohol.

En la IEA se producen efectos reforzadores positivos y negativos. Se potencian los efectos sedativos favoreciendo la neurotransmisión inhibitoria más que la excitatoria, sobre todo por activación de receptores GABAA. La vulnerabilidad es mayor en el sexo femenino y menor en alcohólicos, que constituye un marcador dinámico predictor de mayor riesgo de alcoholismo, hijos de padres alcohólicos y varones con personalidad antisocial y abuso o dependencia de sustancias. Además, la ADH y ALDH difieren genéticamente según la raza.

Todas las embriagueces son patológicas. En las Embriagueces Típicas los efectos psicopatológicos son inversamente proporcionales a la tolerancia y directamente a la concentración sanguínea de Etanol. Las Atípicas presentan dosis-respuesta desproporcionada.

Palabras claves: Intoxicación etílica aguda, embriagueces atípicas, intoxicaciones combinadas, resaca.

\begin{abstract}
Acute Ethanol Intoxication (AEI) is the most common organic disorder induced by alcohol and the most acute frequent intoxication in our medium. It affects $1.1 \%$ of the population, particularly males between the age of $19-28$ years. The $L D_{50}$ dose is $5 \mathrm{gr} . / \mathrm{l}$ with approximate ingestion of alcohol of $3 \mathrm{gr} /$ $\mathrm{Kg}$. weight. The ethanol coma mortality rate is $5 \%$.

In $A E I$, the risk of suffering CET and Subdural Hematoma is more than double and this increases the risk of convulsions, suicide attempts and combined intoxications.

A hangover is more prevalent in low and moderate alcohol consumers.

In AEI, positive and negative reinforcing effects are produced. The sedative effects are increased, favouring inhibitory rather than excitatory neurotransmission, most of all from activation of the GABAA receptors. Vulnerability is higher in the female sex and lower in alcoholics which constitutes a dynamic marker predictor of a greater risk of alcoholism in children of alcoholic parents and males with antisocial personalities and substance abuse or dependency. In addition, the ADH and ALDH differ genetically according to race.

All inebriations are pathological. In typical inebriations, the psychopathological effects are inversely proportionate to tolerance and directly proportionate to the blood concentration of ethanol. Atypical ones present a disproportionate doseresponse.
\end{abstract}

Keywords: acute ethanol intoxication (AEI), atypical inebriation, intoxications, hangover. 


\section{INTRODUCCION}

a Intoxicación Etílica Aguda (IEA) es un síndrome clínico producido por el consumo de bebidas alcohólicas de forma brusca y en cantidad superior a la tolerancia individual de la persona. Dependiendo de la cantidad ingerida de alcohol y de la tolerancia, el curso puede oscilar desde leve desinhibición, hasta coma, depresión respiratoria y muerte.

Rodríguez Martos ${ }^{1}$ traduce la definición que Keller $^{2}$ hace en el Dictionary of Words about Alcohol (DWA) sobre la IEA como: "estado de embriaguez derivado de los efectos del etanol sobre el organismo que pueden revestir distintos grados de gravedad". Diferencia la IEA producida tras la ingestión de alcohol, como resultado del efecto tóxico directo del alcohol sobre el S.N.C., advirtiendo sobre la ambigüedad del término "agudo" que puede significar desde "breve" por la duración a "grave" por las repercusiones.

Es el trastorno mental orgánico más común inducido por el alcohol. Si no contabilizamos las intoxicaciones alimentarias, la IEA es la causa más frecuente de intoxicación aguda en nuestro medio ${ }^{3}$ donde existe una gran tolerancia social, sobre todo en adolescentes, jóvenes y en fines de semana y festivos. Diferentes estudios epidemiológicos nacionales refieren que el 2-7 \% de la población está dentro del grupo de bebedores excesivos (consumo superior a $80 \mathrm{gr}$./día) ${ }^{4}$. Según datos del World Drinks Trends del $1996^{5}$, España es el $5^{\circ}$ país consumidor de alcohol, con 10,2 litros per cápita. Según resultados de estudios de urgencias cifran los cuadros de IEA en el $17-70 \%$ de los pacientes atendidos por conductas violentas. Se estima que la prevalencia para bebedores de riesgo es del $4 \%{ }^{6}$. El perfil del bebedor excesivo, es el de varón, mayor de 26 años (entre 46, y 65 años de edad) de clase media baja y población pequeña ${ }^{4}$. Datos de la encuesta domiciliaria sobre consumo de drogas en 1997', señalan que el 9,9\% tienen consumos por encima del límite de riesgo y el $1,1 \%$ de la población de bebedores y no bebedores se embriaga a diario (291.000 personas). El perfil de los que se embriagan es el de varón entre 19- 28 años, bebedor de diario o de 1-2 veces por semana.

Mediante técnicas de neuroimagen se ha podido comprobar que la administración aguda de etanol disminuye el metabolismo cerebral de la glucosa y aumenta el flujo sanguíneo cerebral. En pacientes alcohólicos, la administración aguda de alcohol disminuye la respuesta subjetiva de intoxicación y aumenta la respuesta metabólica. Estudios con SPECT o PET han puesto de manifiesto una posible disfunción serotoninérgica con menor sensibilidad para la intoxicación alcohólica en varones jóvenes, con rasgos de personalidad antisocial y mayor riesgo de abuso y dependencia de alcohol. La activación de los receptores GABA puede contribuir a los efectos de la IEA De otro lado, los sistemas dopaminérgicos intervendrían más en el inicio y mantenimiento de las respuestas reforzadas por el alcohol ${ }^{8}$.

\section{INTOXICACION ETILICA AGUDA. ASPEC- TOS BIOQUIMICOS}

El alcohol etílico o etanol es un líquido claro, incoloro, volátil, inflamable, muy hidrosoluble, soluble en cloroformo y éter, 30 veces menos liposoluble que hidrosoluble. Es una molécula pequeña y poco polar, que químicamente pertenece al grupo de los Alcoholes alifáticos de cadena corta, y por tanto interacciona fácilmente con grupos polares y no polares de componentes de la membrana con gran capacidad de difusión en medio acuoso y lipídico. Esto explica que atraviese fácilmente la barrera hematoencefálica y llegue a cerebro en breve tiempo tras la ingesta enólica ${ }^{8}$. Su aporte energético es de 7,1 kcal/gr, sin aportar minerales, proteínas o vitaminas.

El etanol se obtiene por fermentación anaeróbica de los Hidratos de Carbono "Fermentación alcohólica" o por "Destilación" de las bebidas fermentadas. Además de actuar como droga psicotropa y a diferencia de otras sustancias adictivas, el etanol es un tóxico 
celular y su consumo produce alteraciones multiorgánicas y daños irreversibles orgánicos que incrementan la morbi-mortalidad ${ }^{9}$.

Las bebidas alcohólicas contienen etanol como principal componente y responsable de las repercusiones orgánicas pero además, contienen otros compuestos, sobre todo las bebidas fermentadas que aumentan el daño fundamentalmente en los episodios de consumos elevados. Se trata de alcoholes de bajo peso molecular (metanol, butanol), aldehídos, ésteres, histamina, fenoles, taninos, hierro, plomo y cobalto ${ }^{10,11}$.

\section{ASPECTOS FARMACOCINETICOS DE- TERMINANTES EN LA I.E.A.}

La intoxicación etílica aguda viene determinada por la concentración de etanol en sangre dentro de una gran variabilidad individual $^{12}$. El alcohol ingerido por vía oral se absorbe principalmente en el intestino delgado en un $80 \%$ y en el estómago en el $20 \%$ por difusión simple a través de las membranas gastrointestinales. También puede absorberse a través de piel y vía inhalatoria. La velocidad de la absorción es proporcional a su presencia en el intestino delgado y aumenta pues en todas las situaciones que favorecen un vaciado gástrico rápido, con ausencia de alimento en el estómago al beber, con la cantidad de alcohol ingerida, los grados de alcohol de la bebida, la rapidez de la ingestión, la ausencia de proteínas, grasas o carbohidratos en el estómago, que interfieren en el proceso de absorción ${ }^{12}$. El consumo de bebidas gaseadas, ejemplo cava o vino con gas, destilados con bebidas carbonatadas, ejemplo cubalibre, aumenta la velocidad de absorción. La temperatura de la bebida- las bebidas frías se absorben más rápidamente. Las concentraciones de alcohol por debajo del $10 \%$ o por encima del $30 \%$ se absorben más lentamente que las concentraciones entre el $15 \mathrm{y}$ el $30 \%{ }^{10}$. Tras la absorción, el alcohol atraviesa el hígado donde es metabolizado el $90 \%$ del alcohol ingerido por oxidación primero de eta- nol a acetaldehido por la vía Alcohol-deshidrogenasa que a pesar de algunas variaciones individuales mantiene una velocidad de metabolización constante e independiente de los niveles plasmáticos de etanol pudiendo oscilar entre 0,15 y 0,25 gr./ I./ hora, de modo que una persona con alcoholemia de $1 \mathrm{gr}$./l. necesitará sobre 6 horas para metabolizarlo. Hay otra vía, la Microsomal que es la vía secundaria de metabolización. La velocidad de metabolización es concentración-dependiente. Es una vía inducible tras la ingesta masiva de alcohol si la vía principal es insuficiente. El $10 \%$ de metabolización de alcohol en la IEA se realiza por esta vía. También se metabolizan gran número de fármacos y es relevante en las interacciones medicamentosas entre alcohol y fármacos. Una tercera vía es la Catalasa, inducible tras la ingesta de alcohol. El sistema Catalasa es muy activo a nivel del cerebro ${ }^{8}$. Diversos hallazgos sugieren que la Catalasa intervendría en algunos efectos farmacológicos y conductuales del etanol ${ }^{9}$. Posteriormente el acetaldehído es oxidado a acetato por la ALDH. Sólo una pequeña parte del acetaldehido no es oxidada y puede pasar como tal a sangre y llegar al cerebro. El acetaldehido atraviesa con dificultad la barrera hematoencefálica y no pasa al cerebro, pero desde hace tres décadas se le relaciona con algunos efectos psicofarmacológicos y neurotóxicos del etanol ${ }^{9}$. Según esta hipótesis el cerebro tendría sistemas enzimáticos propios que metabolizan el alcohol. Se ha detectado sistema activo de catalasa cerebral y el acetaldehido originado sería el responsable de estos efectos ${ }^{9}$. El tercer paso es la Biotransformación del Acetato a Acetil-CoA y su paso al ciclo de $\mathrm{Krebs}^{13}$. Hay una parte que se metaboliza en el estómago por la enzima alcohol-deshidrogenasa gástrica (ADH). La $\mathrm{ADH}$ es menor en las mujeres por lo que a igual consumo de alcohol que el varón, la concentración en sangre en la mujer será más elevada. Asimismo la mujer tiene menor contenido de agua corporal y mayor contenido de grasa que el varón. Por todo ello las concentraciones de alcohol en sangre en la mujer son mayores que en el hombre a igual- 
dad de cantidad de alcohol ingerido por kilo de peso.

Entre un 2\% - 10\% del etanol, con variación dosis-dependiente, se elimina sin metabolizar, a través de respiración, orina y sudor que nos permite determinar indirectamente la alcoholemia. De ahí su importante interés toxicológico y legal ${ }^{10}$.

La concentración de etanol en sangre está equilibrada con la concentración en aire alveolar en proporción 1:2000 a 1 :2.300- el etilómetro estima la concentración de etanol en sangre a partir de la concentración en aire espirado. Son muy utilizados en situaciones relacionadas con el tráfico y debería ampliarse su uso en casos de I.E.A, sobre todo en servicios de urgencias donde conoceríamos con precisión y rapidez la concentración de alcohol en el paciente que sospechemos.

Las enzimas ADH y ALDH muestran expresión genética diferente según los distintos grupos raciales. La respuesta a la ingesta de alcohol presenta cierto grado de variabilidad individual.

Hay estudios que evidencian que en el $40 \%$ de los orientales la ALDH es inactiva, y se produciría una intoxicación acetaldehídica que actuaría como disuasorio en el consumo de alcohol.

Una vez metabolizado el alcohol se distribuye en el organismo alcanzando su nivel máximo de concentración en sangre entre los 30 y 90 minutos desde que se ingiere. Atraviesa fácilmente la barrera hematoencefálica y placentaria y en un $95 \%$ pasa a leche materna.

\section{INTOXICACION ETILICA AGUDA. ASPEC- TOS NEUROBIOLOGICOS}

El alcohol es una droga psicotropa, fundamentalmente depresora del SNC, con acción reforzante positiva, con capacidad de crear dependencia psicofísica, tolerancia y adicción ${ }^{9}$. Ingerido de forma aguda, produce una activación del circuito de recompensa cere- bral, induciendo una sensación subjetiva agradable de euforia, desinhibición, sedación e inducción del sueño, que son efectos reforzadores positivos relacionados con el aumento de la transmisión dopaminérgica ${ }^{8}$.

Sobre otros sistemas de neurotransmisión la ingesta aguda de alcohol puede inducir una sensación subjetiva de alivio de estados emocionales desagradables, como estados de ansiedad y de angustia, fobias, disforia, insomnio, mal humor, preocupación, culpabilidad, depresión, inseguridad y síntomas de abstinencia en pacientes con dependencia. El efecto de alivio inmediato del malestar emocional produce un efecto reforzador negativo. Los efectos reforzadores agudos del alcohol son regulados por el sistema de la amígdala ampliada. Los efectos del consumo agudo de etanol con sus propiedades reforzadoras juegan un papel importante en el desarrollo de la dependencia alcohólica. Sobre los efectos neuroendocrinológicos, la administración aguda de etanol produce un aumento de las concentraciones de la hormona corticotropina (ACTH) y de corticoesteroides, debido al efecto estimulante sobre la secrección del factor liberador de corticotropina (CRF) y de vasopresina.

En pacientes que han desarrollado tolerancia, la administración de dosis elevadas de alcohol puede inducir sensibilización, caracterizada por un estado de "prominencia incentiva" con incremento del deseo de beber y puede estar relacionado con fenómenos como el "craving" (previo al consumo), "priming" (posterior al inicio del consumo) y pérdida de control o consumo compulsivo ${ }^{8}$.

Se creía que el etanol ejercía su acción depresora del S.N.C. al disolverse en las membranas lipídicas. El etanol era una sustancia sin receptor. Pero en los últimos años, numerosos estudios ${ }^{9}$ se han centrado en la investigación de los receptores diana del etanol. La utilización de proteínas recombinantes ha permitido abordar la interacción del etanol con distintas proteínas (canales iónicos, receptores, enzimas involucradas en la traducción de señales). 
Desde los estudios de Meyer y Overton a principios del siglo XX y Seeman en 1.972, un elevado número de estudios demuestran que el etanol a elevada concentración es capaz de fluidificar los lípidos y alterar las proteínas de las membranas neuronales. Y sus alteraciones en la función y respuesta de los receptores nos pueden explicar algunos efectos farmacológicos del etanol, aunque hay varias limitaciones a esta hipótesis ${ }^{9}$.

En cuanto a la acción aguda del Etanol sobre receptores asociados a canales iónicos hasta ahora conocemos que los principales sistemas de neurotransmisores implicados en los efectos agudos del Etanol son el sistema Gabaérgico y el Glutamatérgico ${ }^{14,15}$. La participación de cada uno de los receptores variará según la dosis ingerida de alcohol, concentración sanguínea y duración de la ingesta. Así, dosis bajas de etanol inhiben los sistemas de neurotransmisión inhibidores de la actividad cortical. Ello genera una desinhibición cortical que a nivel popular es valorada como un efecto estimulante del alcohol. Dosis elevadas de etanol, incrementan la depresión central. A concentraciones $>100$ $\mathrm{mM}$ el etanol puede interaccionar con los lípidos de la bicapa lípidica y modificar microdominios de la interacción lípido-proteína o interaccionar con los grupos polares de los fosfolípidos de membrana modificando los microdomios de algunas proteínas ${ }^{9}$.

A continuación resumiremos los efectos agudos del etanol sobre los diferentes neurotransmisores:

\subsection{EL ÁCIDO GAMMA AMINOBUTÍRICO $O$ GABA.}

Es el principal neurotransmisor inhibidor en el cerebro y se activa a través de 2 receptores GABAA y GABAB que están ampliamente distribuidos en el cerebro, cerebelo y tronco cerebral.

En la intoxicación aguda por etanol se potencia la acción del Gaba A favoreciendo el flujo masivo de Aniones $\mathrm{Cl}$ en el interior de las neuronas que conlleva hiperpolarización neuronal y disminución de la excitabilidad que explicaría en parte los efectos depresores del alcohol sobre el S.N.C.

El paralelismo en las acciones farmacológicas del Etanol, Barbitúricos y BDZ sugirió que las tres sustancias tendrían el mismo mecanismo de acción así como la dependencia y tolerancia cruzada que existen entre ellos sobre el Gaba A. Estudios in vitro e in vivo han demostrado que el Etanol potencia el efecto del GABA sobre la actividad neuronal actuando sobre el receptor GABA A y podría ser el mecanismo neurobiológico de la acción ansiolítica del alcohol.

Pero, dada la heterogeneidad de las subunidades del GABAA el efecto estimulante del etanol varía según la región del cerebro estudiada. Así el etanol interacciona con un subtipo de receptor GABAA que posee la subunidad a6 y que se expresa en las células granulares del cerebelo. Se ha postulado que la presencia de este subtipo en el cerebelo podría estar implicada en las alteraciones motoras que se observan en la IEA, ya que la administración de agonistas para las BDZ las previenen?.

Los receptores GABAA de las células de Purkinje del cerebelo encargadas de la posición corporal en el espacio y de la coordinación motora, son sensibles al etanol. La inhibición, por la potenciación que el etanol ejerce sobre el GABA, induce los síntomas cerebelosos de intoxicación alcohólica como aumento del balanceo corporal e incoordinación motora. Los síntomas de intoxicación tras consumo de Alcohol y BDZ son menores en personas más vulnerables al alcoholismo, y más con antecedentes del alcoholismo paterno ${ }^{8}$. Estudios de neuroimagen confirman una respuesta menos intensa, con disminución del metabolismo cerebral de la glucosa tras la administración de 2 mgr de Lorazepam $^{8}$.

Hallazgos genéticos recientes relacionan menor sensibilidad al Alcohol y Diazepam, con un polimorfismo en el gen de la subunidad 6 del receptor GABA-BDZ que podría ser un factor neurobiológico relacionado con el 
abuso de ambas sustancias y ser transmitido genéticamente ${ }^{8}$.

\subsection{EI N METIL D ASPARTATO (NMDA).}

El glutamato es el principal neurotransmisor excitador en el SNC y ejerce su acción a través de receptores NMetil DAspartato (NMDA), el Kainato y el ácido aminopropiónico (AMPA). La unión del glutamato al receptor NMDA promueve la entrada de calcio en la célula.

La administración aguda de etanol tanto a elevadas dosis como a bajas dosis bloquea el receptor NMDA inhibiendo la entrada de iones calcio, bloqueo que puede a su vez contribuir a inhibir la liberación de otros neurotrasmisores como Dopamina o Noradrenalina.

El etanol parece que actúa sobre el locus de la glicina. En la IEA la inhibición del NMDA origina descenso del flujo de iones Ca a través del canal, efecto que puede ser antagonizado por dosis elevadas de glicina ${ }^{16}$. Pero hay estudios que apoyan la variabilidad de respuesta de los receptores NMDA al efecto del etanol en cerebro según la zona: hay marcada inhibición en hipocampo y culículo inferior, y no existe apenas inhibición en el septum lateral ${ }^{9}$.

En el receptor NMDA, la combinación de la subunidad NR1 con la variante NR2B es particularmente susceptible al efecto inhibidor del etanol$^{9}$. El NMDA también tiene un papel importante en la memoria, en la excitabilidad neuronal y convulsiones, en el daño cerebral excitatorio y desarrollo neuronal ${ }^{15}$. La potenciación del NMDA a largo plazo está implicada en procesos de memoria y aprendizaje. El etanol inhibe la potenciación a largo plazo en neuronas del hipocampo tanto in vivo como in vitro. Por tanto, episodios de pérdida de memoria transitoria que se dan en la IEA podrían estar relacionados con inhibiciones puntuales del receptor NMDA en hipocam$\mathrm{po}^{9}$. Se ha comprobado que los fetos pueden ser más sensibles que los adultos a la exposición al alcohol agudo por alteración de procesos de plasticidad y excitotoxicidad mediados por receptor NMDA.

\subsection{OTROS RECEPTORES IONOTRÓPICOS.}

En la intoxicación moderada, el alcohol potencia el efecto de la acetilcolina sobre los receptores nicotínicos. El consumo de alcohol y nicotina suelen ir asociados, esto sugiere que el etanol podría actuar sobre los receptores nicotínicos cerebrales. En la ingestión aguda de alcohol se potencia la neurotransmisión a nivel del receptor nicotínico cerebral. Este efecto se ha relacionado con la estimulación motora que producen bajas dosis de etanol y con la mediación de las propiedades de recompensa del etanol ${ }^{8}$.

\subsection{CANALES DEL CALCIO O CANALES DEPENDIENTES DE VOLTAJE.}

Los canales de Calcio dependientes de voltaje son inhibidos por la administración aguda de Etanol produciendo una reducción de la entrada de calcio en las células. Esto podría relacionarse con sus efectos sedativos e hipnóticos. Numerosos trabajos ${ }^{9}$ indican que altas concentraciones de etanol inhiben los canales tipo L, N y T pero no actúan sobre los de Tipo P. Hay autores que apuntan que el etanol podría interaccionar específicamente sobre la proteína del canal iónico, pero los mecanismos implicados en la acción del Etanol en la regulación del calcio y su trascendencia en la IEA no está totalmente esclarecida.

\subsection{RECEPTORES SEROTONINÉRGICOS.}

En la intoxicación moderada, el alcohol potencia el efecto de la $5 \mathrm{HT}$ sobre los receptores 5HT3 (el único ligado a un canal iónico). Estudios de microdiálisis cerebral ${ }^{8}$ han comprobado que el etanol agudo induce liberación de Dopamina y también de Serotonina en el núcleo accumbens, por lo que los sistemas serotoninérgicos pueden ser mediadores importantes de las acciones del etanol sobre la neurotransmisión dopaminérgica.

La administración aguda de etanol induce un aumento de la liberación y "turnover" de 
serotonina cerebral, que en la ingesta crónica está disminuida. Se ha asociado la disminución en la transmisión serotoninérgica cerebral con trastornos de control de impulsos, trastornos afectivos y agresividad. La ingesta aguda de alcohol eleva la serotonina con efecto reforzador negativo relacionado con alivio de estados emocionales desagradables, disforia, trastornos afectivos y control de impulsos ${ }^{9}$.

\subsection{RECEPTORES DOPAMINERGICOS.}

El efecto reforzador positivo de sustancias psicotropas está relacionado con su capacidad para activar el sistema dopaminérgico mesolímbico. El Etanol aumenta el "turnover" de la Dopamina. Ténicas de microdiálisis cerebral demuestran que la administración sistemática de etanol produce un incremento de la dopamina liberada en el N. Accumbens ${ }^{8}$. La acción aguda del Etanol actuando en el área tegmental ventral del mesencéfalo, incrementa de forma indirecta un aumento de la frecuencia de descarga de las neuronas dopaminérgicas mesolímbico-corticales, mediante una atenuación del tono inhibitorio que ejercen las interneuronas Gabaérgicas.

\subsection{SISTEMA OPIOIDE.}

El etanol y los opiáceos presentan efectos farmacológicos y adictivos parecidos por lo que pueden tener un sustrato neurobiológico común. El Etanol activa los receptores opioides. La administración aguda de alcohol produce un aumento de la expresión génica de endorfinas y encefalinas en cerebro:

A modo de conclusión podemos decir que las funciones cerebrales dependen de un equilibrio entre neurotransmisión excitatoria e inhibitoria. La administración aguda de alcohol inclina el equilibrio a favor de la inhibición, potenciándose los efectos sedativos por bloquear factores de irritabilidad neuronal o por potenciar neurotransmisores inhibidores como el Gaba. (TABLA I)

\section{TABLA I. NEUROBIOLOGIA DEL CONSUMO AGUDO DE ALCOHOL.}

\begin{tabular}{lcl}
\hline \multicolumn{3}{c}{ EFECTOS AGUDOS } \\
\hline SISTEMA & EFECTO FARMACODINAMICO & EFECTO CLINICO \\
\hline NMDA & - & Sedación, amnesia \\
GABA A & + & $\begin{array}{l}\text { Sedación, activación, } \\
\text { euforia, ansiolisis. }\end{array}$ \\
NA & + & Activación \\
5 ht-3 & + & Ansiolisis, náuseas. \\
DA & + & Activación, euforia. \\
OPIOIDE & + & Euforia \\
MUSCARÍNICO & - & Amnesia \\
ADENOSINA & + & Incoordinación /Sedación \\
Canales del Ca ++ & & \\
\hline Rubio G; 2000 & & \\
NMDA $=$ N-Metil-D-Aspartato GABA=Acido gamma butírico, NA= Noradrenalina. & \\
5-HT = Serotonina, DA =Dopamina (+)=activación /estimulación, (-)=inhibición. & \\
\hline
\end{tabular}

\section{VULNERABILIDAD GENETICA}

La administración de elevadas dosis de alcohol en hijos de alcohólicos producen niveles más bajos de prolactina, menor sensación subjetiva de intoxicación etílica, menores decrementos en los rendimientos cognitivos y psicomotor y bajos niveles de cortisol y ACTH. La menor sensación subjetiva de intoxicación alcohólica y el menor balanceo cor- 
poral o ataxia estática tras la ingesta de elevadas cantidades de alcohol es un marcador dinámico predictor de mayor riesgo de alcoholismo ${ }^{17}$. Hijos varones de padre alcohólico con baja respuesta al alcohol a los 20 años, tienen mayor riesgo de desarrollar alcoholismo hacia los 30 años de edad- por lo que el nivel de reacción al alcohol, puede ser un mediador de riesgo del alcoholismo ${ }^{17}$. La regulación genética del receptor GABAA puede ser un factor importante que influya en la respuesta al etanol. Hay hallazgos genéticos que relacionan la menor sensibilidad al alcohol y al diacepam con un polimorfismo del gen de la subunidad a6 del receptor GABA-BDZ, sería un factor neurobiológico trasmitido genéticamente y predictor de riesgo de abuso de alcohol y BDZ sobre todo en hijos de alcohólicos.

\section{CLÍNICA DE LA INTOXICACION ETILICA AGUDA.}

\subsection{ASPECTOS PSICOPATOLOGICOS}

\subsubsection{EMBRIAGUEZ SIMPLE O TIPICA.}

La intoxicación por alcohol es el trastorno mental orgánico más común ${ }^{18}$, es de duración limitada y dentro de una variabilidad individual puede presentarse el cuadro con diferentes cantidades de alcohol. La intensidad de los efectos es inversamente proporcional a la tolerancia desarrollada por la persona y a nivel central es directamente proporcional a la concentración de etanol en sangre, y ésta a su vez depende de la cantidad de alcohol ingerida y graduación, de la velocidad de absorción digestiva, de la cantidad de líquido que se beba con el alcohol (que diluirá su concentración en sangre), del peso del paciente y del tiempo que haya pasado tras su consumo'. Dentro de una variabilidad individual, en el consumo agudo de alcohol existe una relación más clara entre las concentraciones de etanol en sangre y el perfil de los efectos farmacológicos. El troncoencéfalo y la sustancia blanca cerebral se afectan antes que la corteza.

El alcohol es prioritariamente un depresor de la transmisión nerviosa en el S.N.C. y presenta tolerancia cruzada con otros psicotropos depresores del S.N.C. Las alteraciones del S.N.C. son los primeros síntomas que aparecen en el paciente. Desde el punto de vista psicopatológico lo más relevante son los cambios conductuales que aparecen tras la ingestión de alcohol.

En la IEA típica si relacionamos la sintomatología con las concentraciones de etanol en sangre encontramos diferentes estadios (Tabla II) en una persona que no haya desarrollado tolerancia al alcohol.

Se observan síntomas clínicos con concentraciones bajas de etanol en sangre entre $20 \mathrm{y}$ $30 \mathrm{mgr} / \mathrm{dl}$. que la persona refiere como "estimulación" y es debido a la inhibición de mecanismos inhibidores de control nervioso, en concreto inhibidores de la formación reticular que controla la actividad asociativa. Hay autores que sugieren efectos estimulantes directos del alcohol a bajas concentraciones y efectos ansiolíticos. En conjunto los efectos de "pseudoexcitación", sensación de euforia, optimismo, aumento de sociabilidad, conducta espontánea y menos autocontrolada y sobrevaloración personal se asocian a alteraciones importantes del rendimiento psicomotor, disminución de habilidad psicomotora fina, aumento del tiempo de reacción a estímulos y pérdida de la capacidad de concentración. Deterioro de la acomodación y de la capacidad para seguir objetos, reducción del campo visual y alteración de la visión periférica.

Concentraciones de etanol mayores (entre 100-150 mg/dl) conlleva mayor depresión central con sintomatología más relevante a nivel psicológico y psicomotor, torpeza expresiva y motora (disartria y ataxia), pérdida de reflejos, sopor y sueño ${ }^{16}$. Concentraciones más elevadas (entre 400 y $500 \mathrm{mg} / \mathrm{dl}$ ) producen coma, depresión bulbar, e incluso, muerte ${ }^{19}$.

Cuando se ha desarrollado neuroadaptación y tolerancia al alcohol por consumo crónico, el cuadro desarrollado a igualdad de concentra- 


\section{TABLA II. ESTADIOS DE LA INTOXICACIÓN ALCOHOLICA}

\section{ALCOHOLEMIA EFECTOSY ALTERACIONES EN LA CONDUCTA (MG/100 ML)}

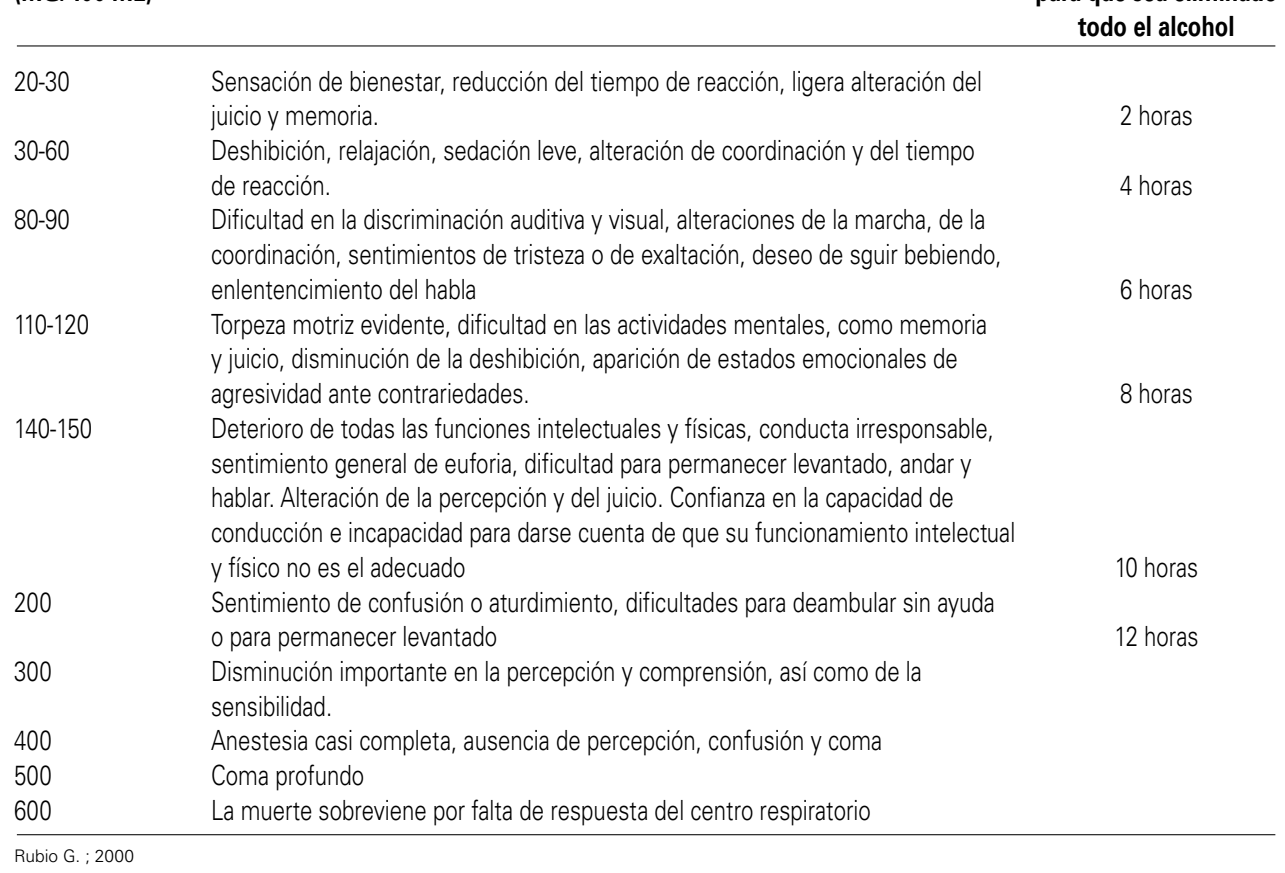

ción de etanol en sangre es diferente disminuyendo en estos casos los efectos motores, sedantes, ansiolíticos y anestésicos.

\subsubsection{EMBRIAGUECES ATÍPICAS.}

Partiendo de la consideración de que todas las embriagueces son anormales y patológi$\operatorname{cas}^{19}$, las embriagueces atípicas pueden serlo por su calidad o por su intensidad', pudiendo incluir:

A) Intoxicación Alcohólica Aguda con manifestaciones Psicóticas - DSM III 303.00

B) Intoxicación Alcohólica Atípica. Ésta debe su nombre a la dosis-respuesta desproporcionada con cambios graves y bruscos en el comportamiento asociado a agresividad física o verbal, agitación y en ocasiones ilusiones y/o alucinaciones que siguen a la ingesta de cantidades relativamente pequeñas de alcohol (las concentraciones de etanol en sangre suelen ser menores a $40 \mathrm{mgr} / 100 \mathrm{ml}$.). La mayor parte de personas no presentan intoxicación con estas cantidades de alcohol. El cuadro se inicia a los poco minutos de la ingesta, de forma brusca, con conciencia obnubilada y sin coordinación. Tras 2 ó 3 horas de evolución el cuadro remite, entrando en un sueño profundo y suelen presentar amnesia parcial o total del episodio ${ }^{1}$.

El cuadro es atípico en el sentido de que no se presenta cuando el individuo no ha bebido'.

Clásicamente según la sintomatología se diferencian los siguientes tipos ${ }^{20}$ :

B.1. Embriaguez excitomotriz, con manía furiosa o clástica. Se manifiesta por impulsos motores destructivos. Cursa con riesgo elevado de auto y heteroagresividad. 
B.2. Embriaguez maniacodepresiva. Se manifiesta con episodios cortos de manía con euforia y expansividad, o con episodios de depresión con desinhibición. Cursa con elevado riesgo autolítico. B.3. Embriaguez delirante. Se manifiesta con megalomanía, celotipia, ideas persecutorias y autoacusación. Cursa con riesgo autolítico elevado.

B.4. Embriaguez alucinatoria. Se manifiesta por alucinaciones auditivas y / o visuales de contenidos violentos. Cursa con hetero y autoagresividad graves.

B.5. Embriaguez convulsiva o epileptiforme de Kraepelin

B.6. Embriaguez pseudorrábica, denominada de Lereboullet. Caracterizada porque el paciente se tira a morder a las personas. Cursa con importante componente histriónico.

El trastorno es más frecuente en varones mayores y tiende a repetirse en el mismo sujeto. Aparece con mayor frecuencia en pacientes con patología y/o tratamientos psiquiátricos: hipnóticos y sedantes, trastorno explosivo intermitente, trastorno del control de impulsos, epilepsias con crisis del lóbulo temporal (crisis parciales complejas), trastornos cerebrales orgánicos como Traumatismos Craneoencefálicos (TCE) y encefalitis, histéricos, esquizofrénicos, psicópatas, pacientes con insomnio, en intensos estados de excitación sexual y en pacientes con Linfoma de Hodking. Son muy raras en individuos sanos ${ }^{20}$. Se cree que se trata de una predisposición personal especial y no se incluye como tal en el DSM-IV, debiendo tipificarse como Intoxicación por alcohol o Trastorno relacionado con el alcohol no especificado DSM-IV²1.

\subsection{CRITERIOS DIAGNÓSTICOS}

EI DSM-IV²1 para el Diagnóstico de Intoxicación Etílica por Alcohol incluye además de la ingestión reciente de alcohol, cambios psicológicos comportamentales desadaptativos durante la intoxicación de alcohol o pocos minutos después de la ingesta de alcohol y al menos uno de los siguientes síntomas: lenguaje farfullante, incoordinación, marcha inestable, nistagmo, deterioro de la atención o de la memoria, estupor o coma.(Tabla III).

Concentraciones mínimas entre 50-100 $\mathrm{mg} / 100 \mathrm{ml}$ de etanol en sangre tienen poca relevancia en las manifestaciones clínicas. Concentraciones de etanol en sangre entre 100-200 mg/100 ml se asocian a euforia, excitación, verborrea, actitud discutoria, labilidad afectiva, desinhibición de impulsos sexuales agresivos ${ }^{22}$, disminución del rendimiento intelectual y alargamiento del tiempo de reacción a estímulos.

Concentraciones de etanol en sangre entre $200-300 \mathrm{mg} / 100 \mathrm{ml}$ se asocian a alteraciones de la coordinación motora, ataxia, disartria, obnubilación progresiva, nistagmo, dificultad para mantenerse en bipedestación, reducción del nivel de consciencia y alteraciones de las funciones mentales superiores, concentración, orientación, memoria, atención y juicio.

Concentraciones superiores a 300-500 $\mathrm{mg} / 100 \mathrm{ml}$ de etanol en sangre pueden producir coma profundo. Dosis superiores de etanol en sangre se consideran letales.

La dosis letal en el $50 \%$ de casos( DL 50) es de $5 \mathrm{gr} / \mathrm{l}$. que corresponde a una ingesta de alcohol aproximada de $3 \mathrm{grs} / \mathrm{kg}$ de peso según Odermatt ${ }^{3}$. Los cuadros más graves de IEA pueden causar coma, depresión respiratoria y muerte. La muerte sobreviene por parada cardio-respiratoria por múltiples causas: broncoaspiración de contenido gastrointestinal, coma acidótico, hipoglucémico o por enfriamiento y depresión bulbar. La mortalidad asociada al coma etílico es del $5 \%$.

Unido al cuadro neurológico se asocian alteraciones vasomotoras como inyección conjuntival y rubor facial que junto con fetor enólico y signos vegetativos facilitan al clínico el diagnóstico. A dosis elevadas además de disminuir la temperatura corporal interna, se produce una depresión del mecanismo regulador de la temperatura corporal. Este efecto es más peligroso cuando la temperatura ambiente es muy baja por lo que es necesa- 


\section{TABLA III. CRITERIOS DIAGNÓSTICOS DE LA INTOXICACIÓN ETÍLICA AGUDA}

\section{CRITERIOS DE DIAGNOSTICO DE INTOXICACION POR ALCOHOL SEGÚN EL DSM IV}

-Ingestión reciente de alcohol.

-Cambios psicológicos o comportamentales desadaptativos clínicamente significativos de los que suelen aparecer durante o poco después de su consumo: sexualidad inapropiada, comportamiento agresivo, labilidad emocional, deterioro de la capacidad del juicio y deterioro de la capacidad laboral o social, que se presenta durante la intoxicación o pocos minutos después de la ingesta de alcohol.

-Uno o más de los siguientes síntomas que aparecen durante el consumo de alcohol o poco despues:

- Lenguaje farfullante.

- Incoordinación,

- Marcha inestable,

- Nistagmo,

- Deterioro de la atención o la memoria,

- Estupor o coma.

-Los síntomas no se deben a enfermedad médica o se explican mejor por la presencia de otro trastorno mental.

\section{PAUTAS DE DIAGNOSTICO DE INTOXICACION POR ALCOHOL SEGÚN LA OMS (CIE 10)}

-Estado transitorio consecutivo a la ingestión que produce alteraciones del nivel de conciencia, de la cognición, de la percepción, del estado afectivo, del comportamiento o de otras funciones o respuestas fisiológicas o psicológicas.

-Suele tener una relación estrecha con la dosis ingerida, aunque hay excepciones en individuos con cierta patología orgánica subyacente, en los que dosis relativamente pequeñas pueden dar lugar a una intoxicación desproporcionadamente grave.

-La desinhibición relacionada con el contexto social (por ejemplo, en fiestas o carnavales) debe también ser tenida en cuenta.

-La intensidad de la intoxicación disminuye con el tiempo, y sus efectos desaparecen si no se repite el consumo.

-A dosis bajas predominan los efectos estimulantes sobre el comportamiento. Al aumentar la dosis produce agitación y agresividad, y a niveles muy elevados da lugar a una clara sedación.

rio abrigar suficientemente a la persona intoxicada para evitar mayor pérdida de calor.

En el DSM- IV, la IEA se incluye dentro de los Trastornos Inducidos por Alcohol, y para el diagnóstico nos basamos en la evidencia de que el paciente cumpla los Criterios de Diagnóstico de Intoxicación por Alcohol según el Diagnostic and Statiscal Manual of Mental
Disorders (DSM-IV) bajo el código 303.00 o las Pautas de Diagnóstico de Intoxicación por Alcohol según la OMS (CIE 10) bajo el código F 10.00. (Tabla III) $)^{21,23}$.

Para la exploración del paciente, en la práctica clínica, hemos de tener en cuenta el estado del paciente para colaborar. El objetivo más importante es prevenir y/o tratar las complica- 
ciones derivadas y/o asociadas a la intoxicación, atendiendo especialmente a valorar el estado general y constantes vitales, permeabilización de vías aéreas por atragantamientos o broncoaspiración, valorar depresión respiratoria (midiendo frecuencia respiratoria), sistema circulatorio (midiendo T.A., pulsos periféricos, frecuencia), nivel de conciencia mediante la escala de Glasgow, tamaño y reactividad pupilar. Dada la integridad de la vía neurológica, encontraremos midriasis con reflejo pupilar conservado pero enlentecido y simétrico.Valorar temperatura corporal por hipotermia. Son frecuentes los hematomas faciales y periobitarios por caidas o peleas. Están más expuestos a infecciones por supresión secundaria de los sistemas inmunológicos ${ }^{24}$.

La gravedad de la IEA aumenta cuando concurren circunstancias adversas pero frecuentes, como accidentes de tráfico, de trabajo, domésticos, actos suicidas o delictivos...

Si hay alteraciones de conciencia descartar hipoglucemia, meningismo, focalidad neurológica, acidosis metabólica, pancreatitis, TCE y hematoma subdural ${ }^{25}$. El riesgo de sufrir TCE y hematomas subdurales en los pacientes con IEA es más del doble que en la población general ${ }^{26}$. En estos casos aumentan la mortalidad y la estancia hospitalaria, se retrasa el diagnóstico - a veces ingresan primero en unidades psiquiátricas -, y si se trata de pacientes alcohólicos o con consumos de otros tóxicos es más frecuente que precipiten Delirium Tremens u otros Síndromes de Abstinencia. La recuperación de los pacientes con TCE es más difícil y su tolerancia al alcohol disminuye en el futuro. También son especialmente vulnerables a padecer otras enfermedades.

La entrevista del paciente intoxicado de alcohol, si es posible, ha de ser personal y privada. En todo caso siempre respetuosa, coordial y en un lugar tranquilo, llamando al paciente por su nombre, recordar que es un paciente con baja autocrítica y capacidades cognitivas disminuidas. Evitar la confrontación, facilita la colaboración del paciente y la obtención de información sobre tipo y cantidad de alcohol consumido y consumo actual de otros tóxicos, hábitos de consumo de drogas, enfermedades actuales, tratamientos y su cumplimentación, traumatismos o agresiones asociadas y antecedentes personales ${ }^{14}$. La entrevista a los acompañantes nos confirmará la información facilitada por el paciente.

Algunos pacientes presentan alteraciones de conducta con auto y/o heteroagresividad, otros refieren ideas autolíticas. Normalmente estos síntomas revierten al remitir la intoxicación. Siempre hay que reevaluarle psiquiátricamente en sobriedad por si procede su ingreso en unidad psiquiátrica.

Pruebas biológicas. Incluirán Alcoholemia, analítica general de sangre, perfil hepático y renal, Transferrina deficiente en carbohidratos, Gasometría arterial e iones $\mathrm{Na}, \mathrm{K}$ y Mg. Sistemático de orina y determinación de metabolitos de otras drogas psicoativas en orina. Si hay alteración de conciencia y/o traumatismos completar con estudio EKG, RX, TAC, RM, etc.

Se debe practicar unaexploración física básica, descartar fracturas de cualquier localización, TCE y Hematoma Subdural. Valorar la presencia de signos de focalidad neurológica, pares craneales, sobre todo exploración de pupila, reflejos, tono muscular, sensibilidad y de alteraciones de conciencia (escala de Glasgow) orientación, coordinación motora, concentración, comportamiento, lenguaje, equilibrio en bipedestación y deambulación. Si se trata de un paciente con Dependencia de alcohol, iniciar prevención y/o tratamiento de Síndrome de abstinencia (S.A.A.). Si lo sospechamos estaremos alerta por si aparece hipertensión arterial o frecuencia cardíaca elevadas, así como temblores, ansiedad, irritabilidad, insomnio y miedo que nos orientan al S.A.A..Siempre descartar consumo de otras drogas, sobre todo en pacientes con intento autolítico. Las drogas sedantes como BDZ y opiáceos suelen ser las que se asocian más frecuentemente. También hay mayor riesgo de que aparezcan crisis convulsivas. La exploración psicopatológica debe ser lo más amplia posible, evaluando sobre todo trastornos psicóticos y depresivos. Si apare- 
cen hay que volver a evaluar al paciente cuando haya revertido la intoxicación ${ }^{16}$.

\subsection{DIAGNOSTICO DIFERENCIAL}

Aunque el diagnóstico de IEA sea evidente, si el paciente se encuentra en estado confusional hay que descartar siempre otros cuadros $^{27}$ : Intoxicación por hiposedantes, Intoxicación por Gammahidroxibutírico, estados postictales, Hipoglucemia, Encefalopatía hepática, cetoacidosis diabética, Meningitis, Encefalitis, Hematoma Subdural, Pancreatitis Aguda, Intoxicación por CO, Intoxicación por tóxicos industriales (benzol, gasolina...) e Intoxicación por Alcohol Metílico que se usa en la adulteración de bebidas alcohólicas con riesgo de intoxicación, o con finalidad autolítica o en pacientes que tienen acceso restringido a bebidas alcohólicas. La toxicidad deriva en gran medida de sus metabolitos el formaldehido y el ácido fórmico.

Por tanto es importante tener en cuenta la información del paciente cuando refiere que ha consumido poco alcohol o niega su uso para descartar otros procesos diferenciales ${ }^{3}$.

\section{TRATAMIENTO}

\subsection{ABORDAJE GENERAL DE LA IEA.}

El tratamiento de la intoxicación etílica es sintomático y debe adecuarse según el nivel de conciencia del paciente y el tiempo transcurrido desde la ingesta ${ }^{27}$.

La intoxicación etílica no es un síndrome sin importancia y dado que la patología puede exacerbarse, nos obligará a mantener al paciente en vigilancia médica mientras perdure la intoxicación.

En personas sin dependencia etílica y con intoxicaciones agudas con alcoholemias inferiores a $200 \mathrm{mgr} / 100 \mathrm{ml}$ requieren sólo reposo y observación ${ }^{28}$. Control de constantes y colocar al paciente en habitáculo tranquilo y con poca luz para disminuir los estímulos externos y en decúbito lateral. Si han pasado más de 2 horas de la ingesta se puede remitir al paciente a su domicilio bajo vigilancia familiar. No utilizar tratamiento farmacólogico ya que no se puede acelerar el metabolismo del alcohol ${ }^{29}$.

Si la ingestión de alcohol ocurrió hace menos de 2 horas, la ingesta de café amargo o la provocación del vómito pueden ser útiles, si hace más de 2 horas la absorción es casi completa y estas medidas o duchas de agua fría, o aumento de la actividad motriz tienen escaso efecto.

\subsubsection{En cuadros de Intoxicación Etílica}

Moderada, con estupor de corta duración (obnubilación incipiente, respuesta lenta a estímulos, menor estado de alerta) o ataxia se recomienda además de control de constantes vitales, la administración de una ampolla de $100 \mathrm{mg}$. de Tiamina i.m. en dosis única y $300 \mathrm{mgr} /$ día durante 3 días consecutivos por vía oral ${ }^{3}$. Hay que tener presente el riesgo de hipersensibilidad a la vitamina B1 sobre todo vía parenteral. Su administración intravenosa debe ser lenta y su uso exclusivamente hospitalario y no muy recomendable, aunque hay falta de consenso al respecto.

7.1.2. En cuadros de intoxicación de pacientes con etilismo crónico, es de especial importancia la administración de Tiamina para prevenir Encefalopatía de Wernicke. La administración de soluciones glucosadas siempre será posterior a la de Tiamina, ya que la glucosa acelera su metabolismo y agota las escasas reservas de vitamina B1 en estos pacientes $^{30}$. Si hay shock anafiláctico se administrarán glucocorticoides, antihistamínicos e inclusive adrenalina.

\subsubsection{En Intoxicaciones Etílicas Graves 0} ante riesgo evidente de coma etílico, el tratamiento consiste en mantener constantes vitales y evitar complicaciones como depresión respiratoria, broncoaspiración de vómitos, hipoglucemia o shock. Pacientes estuporosos o comatosos con Glasgow inferior a 10, abolición de reflejo tusígeno o nausígeno, depresión respiratoria, acidosis metabólica, 
tensión sistólica menor de $90 \mathrm{~mm}$. Hg o enfermedad que pueda descompensarse, deben ser tratados en un medio hospitalario ${ }^{31}$. La actitud terapeútica será como sigue:

-Medidas de reanimación para estabilizar las constantes vitales y mantener equilibrio hidroelectrolítico y ácido base por vía parenteral.

-Posición en decúbito lateral del paciente.

-Administración de 100 mgr. de Tiamina preferentemente i.m., como profilaxis del Síndrome de Wernicke. Siempre después, administración de soluciones glucosadas, $20-40 \mathrm{ml}$ al $50 \%$ pueden prevenir que aparezca hipoglucemia ${ }^{28}$.

-Control de Temperatura corporal. Hipotermias inferiores a $31^{\circ} \mathrm{C}$ pueden producir coma.

-Sueroterapia en perfusión de 3.000 cc/24 h. alternando suero glucosado al $5 \%$ y glucosalino para garantizar buena hidratación y porque diluye el etanol hasta en un $20 \%$.

- Lavado gástrico, solo en caso de que hayan transcurrido menos de 2 horas desde la ingesta.

-En alcoholemias > 300-350 mgr/dl se puede recurrir a Hemodiálisis ${ }^{24}$

-En casos graves puede ser necesario intubación e ingreso en U.C.I.

-Si aparecen vómitos, administrar 10 mgr. de Metoclopramida / 8 h. por i.v.

Durante el tiempo que dure el riesgo de presentar coma hay que mantener al paciente hospitalizado y con un buen control de constantes. En general, a las 24 horas el alcohol ya se ha metabolizado y el cuadro remite, salvo en caso de complicaciones. El paciente puede sufrir amnesia parcial o total. Al recuperar la conciencia se presentan sentimientos de culpa, reacciones de ansiedad y frustración siendo conveniente evaluar al paciente por posible riesgo autolítico antes de darle de alta. La actitud del clínico ha de ser de colaboración y orientación al paciente y si existe patología comórbida derivarle a centros específicos de tratamiento.
7.1.4. Tratamiento de las embriagueces atípicas: El tratamiento es de sostén: entorno y actitud relajados con protección mecánica si es preciso y vigilancia estrecha. Tratar la agresividad y la agitación del paciente con BDZ como Diacepam 10-20 mgr. o Cloracepato dipotásico 50-100 mgr. o Neurolépticos como Clotiapina o Halperidol 1 ampolla 5 mgr. i.m. cada 30 minutos hasta la sedación, con un máximo de 30 mgr. mientras no haya hipotensión ${ }^{28}$.

\section{2. TRATAMIENTO DE LAS COMPLICA- CIONES ASOCIADAS A LA I.E.A.}

Hay IEA más graves asociadas a otros cuadros o al consumo de otras drogas psicoactivas:

7.2.1.Crisis Convulsivas: Pueden aparecer durante la intoxicación etílica. Son factores predisponentes la hipopotasemia, hipomagnesemia, antecedentes de epilepsía y la intoxicación o síndromes de abstinencia por benzodiacepinas ( BDZ) o por anticonvulsivantes.

Tratamiento: mantener vía aérea permeable mediante un Guedel, administrar Oxigenoterapia y canalizar vía parenteral. Administración de Diacepam 10 mgr.i.v. Corregir hipomagnesemia e hipoglucemia con suplementos de Magnesio y suero glucosado $5 \%$. Si no hay diagnóstico de Epilepsía no mantener tratamientos con anticonvulsivantes, una vez remitida la crisis.

7.2.2. Agitación psicomotriz : Las IEA suelen cursar con alto grado de agitación y auto o heteroagresividad, siendo preciso la presencia de personal de seguridad y protección mecánica para evitar autolesiones. Extremar el ser respetuosos en el trato con el paciente. Si el paciente colabora, ofrecerle líquidos y sedación oral con Loracepam 1-2 mgr. o Diacepam 5-10 mgr. Si se manteniene agitado, aumentar la sedación. Algunos autores recomiendan BDZ (Diacepam 10 mgr. o Cloracepato dipotásico $50 \mathrm{mgr}$ ) administrados según la urgencia del cuadro vía oral, sublingual, rectal o i.v. En lo posible evitar la administración de BDZ vía 
i.m. porque su absorción es más lenta. No obstante, en la práctica clínica es preciso recurrir a la vía i.m. por el estado de agitación y/o falta de colaboración del paciente. A pesar de que los neurolépticos disminuyen el umbral convulsivante hay autores que prefieren administar 1 ampolla i.m. de haloperidol 5mgr./20-30 mi. al considerar que las BDZ pueden producir parada respiratoria o favorecer la broncoaspiración por exceso de sedación en mayor medida que el haloperidol ${ }^{28}$.

7.2.3. Tentativas de suicidio :Los consumos de alta graduación en jóvenes varones son un factor de riesgo de tentativas de suicidio, generalmente con trastorno depresivo concomitante, historia previa de otras tentativas, aislamiento, marginación social o patologías graves ${ }^{24}$. El $15-20 \%$ de los suicidios consumados se dan en personas con problemas de alcohol.

La IEA en un paciente depresivo produce primero efectos desinhibidores pero después menor capacidad de juicio, mayor agresividad e impulsividad siendo posible que el paciente decida el suicidio como mejor salida a su situación vita ${ }^{32}$. En la clínica, los pacientes se muestran hostiles con el personal y cuando descienden los niveles de alcoholemia comienzan a mejorar su actitud y afloran sentimientos de desesperanza y culpa. Frecuentemente, a la ingestión elevada de alcohol asocian otras drogas que disminuyen el nivel de conciencia. Hay que evaluar al paciente para prevenir síndromes de abstinencia y explorar el trastorno psiquiátrico subyacente, dependencia de sustancias, alcohol, opiáceos, benzodiacepinas, cocaina, cannabis, trastorno depresivo, psicótico o trastorno de personalidad. El tratamiento será el específico según la sustancia utilizada. Dependiendo de la gravedad de la tentativa se procederá a su ingreso en unidad de psiquiatría y/o el tratamiento oportuno.

7.2.4. Intoxicaciones combinadas: El policonsumo es la situación más frecuente en la clínica sobre todo en los jóvenes y adolescentes, pero también en adultos que salen para divertirse, más en fines de semana ,y tienden a consumir diversas drogas al mismo tiempo o correlativamente. Se estima que los alcohólicos tienen siete veces más riesgo que la población general de tener otras dependencias $^{33}$. Las intoxicaciones de dos o más drogas son más graves y de más difícil manejo para el clínico. A mayor consumo de sustancias menor percepción de riesgo asociado al consumo de otras sustancias diferentes.

La intervención terapéutica tiene dificultades: a)el estado de intoxicación puede dificultar la información del paciente acerca del consumo de todas las sustancias, b) minimización del consumo por parte del paciente y/o del terapeuta y c) falta de programas de intervención eficaces que abarquen de forma integral el abordaje terapéutico de pacientes con consumos comórbidos de varias sustancias y que han de contemplar, además de las sustancias consumidas, el estado físico y psíquico del paciente, sus circunstancias personales y el contexto en el que se producen.

Es importante evaluar el consumo de todas y cada una de las sustancias, la secuencia de su uso y la finalidad, explorando las drogas secundarias, minimizadas generalmente, sobre todo si la otra droga es ilegal o si se trata de cafeína o de tabaco. Los pacientes suelen tener más trastornos psiquiátricos, más patologías familiar y social y peor respuesta a intervenciones terapéuticas. Son útiles los controles de tóxicos en orina para el diagnóstico ${ }^{33}$.

Ante toda intoxicación de alcohol es obligado descartar que haya existido consumo de otras drogas, especialmente en los intentos autolíticos. Las drogas que más frecuentemente se asocian son las BDZ y los opiáceos. Si se sospecha y/o confirma el consumo asociado de:

-BDZ: debemos administrar 0,25 mgr/min. de flumazenil (media ampolla de 0,5 mgr. por vía i.v. lenta hasta la recuperación con un máximo 4 ampollas). Cada dosis ha de administrarse durante un tiempo mínimo de 15 segundos para evitar síndrome deprivación. En ocasiones aparece reacción paradójica de desinhibición, agresivi- 
dad, ansiedad, excitación con consumo de BDZ asociado o no al consumo de alcohol Son más frecuentes con BDZ de vida media corta, como el Triazolam y se dan más en ancianos. El tratamiento puede realizarse con neurolépticos o en casos graves flumazenil pero no administrar BDZ para la sedación ${ }^{34}$.

-Opiáceos: administrar una ampolla de naloxona i.v. en bolo (repetible cada 3 minutos hasta 3 dosis). En la clínica, lo sospecharemos si el paciente presenta miosis. Si no hay respuesta, sospecharemos además Intoxicación por BDZ. El flumazenil es útil en el diagnóstico diferencial, en el tratamiento de la intoxicación por BDZ y parece ser beneficioso también en el coma etílico.

-Cannabis: administrar Diacepam 10 mgr. o Cloracepato 50 mgr. si predomina sintomatología ansiosa o crisis de angustia. Con estado confusional o síntomas psicóticos Haloperidol 5-10 mg i.m. Evitar fenotiazinas por posible crisis anticolinérgica.

-Cocaína: Tratamiento sintomático y de sostén. Para la agitación del paciente que suele ser importante, administraremos BDZ. Si presenta convulsiones, Diacepam $10 \mathrm{mgr}$ i.m. Si refiere síntomas psicóticos Haloperidol.

-Anfetaminas: Tratamiento sintomático y de sostén. Suele remitir en 24-48horas. Tratar las convulsiones con Diacepam. La hipertensión arterial con Betabloqueantes adrenérgicos (Labetatol). La agitación con Haloperidol 5-10 mgr., Droperidol (5-15 $\mathrm{mg})$ o Clorpromazina. En ingestas masivas proceder a diuresis forzada con Acidificación de orina.

-LSD: Tratamiento sintomático. Si aparecen Crisis de Pánico administrar BDZ, y es fundamental convencer al paciente de que se encuentra protegido.

-Feniletilaminas: MDA, MDMA (Extasis), MMDA. Tratamiento sintomático.

-Fenciclidina: Acidificación de orina. Administrar Benzodiazepinas. No utilizar fenotiazinas.
-Gammahidroxibutírico: Sus efectos son potenciados por consumo asociado de alcohol, cannabis, benzodiacepinas, neurolépticos y heroína. El tratamiento es sintomático.

-Barbitúricos: Potencian los efectos del alcohol en SNC.Si la ingesta con alcohol ha sido anterior a 2 horas y la conciencia no está deteriorada intentar lavado gástrico y carbón activado. Diuresis alcalina forzada menos con barbitúricos de acción rápida, hasta tener $\mathrm{PH}$ urinario 7,5 ${ }^{34}$.

-Metanol: Si no han transcurrido más de 34 horas hacer lavado gástrico, Alcalinización con Bicarbonato Sódico para corregir la acidosis metabólica. La hemodiálisis consigue buen aclaramiento plasmático de metanol y formaldehido y ácido fórmico ${ }^{3}$.

\section{RESACA}

Se define la Resaca ${ }^{35}$ como el estado caracterizado por la presencia de al menos dos de los síntomas siguientes: cefalea, diarrea, anorexia, temblor, fatiga, naúseas, alteraciones cognitivas, visuo-espaciales, hemodinámicas, hormonales y disminución de la actividad ocupacional, que aparecen tras el consumo y metabolización completa del alcohol con graves repercusiones e interrupción del funcionamiento de las tareas diarias y de las responsabilidades.

La prevalencia es muy elevada y paradójicamente es mayor en bebedores de consumo bajo y moderado de alcohol que en grandes bebedores. La ingesta de 1,5 a 1,75 gr/ kg de peso de alcohol (aproximadamente 5-6 bebidas en un varón de $80 \mathrm{~kg}$ y $3-5$ bebidas en una mujer de $60 \mathrm{~kg}$ ) durante más de 4-6 horas, casi siempre va seguida de síntomas de resaca ${ }^{35}$.

Manifestaciones clínicas y fisiológicas: La severidad de la resaca está directamente relacionada con la cantidad de alcohol ingerida, las impurezas de otros derivados mezclados con el alcohol, la ausencia de alimentos 
en el estómago, la disminución de la cantidad y calidad de sueño, el incremento de la actividad física durante la intoxicación, la deshidratación y la pobre salud física.

Según algunos estudios ${ }^{35}$, el Acetaldehido resultante de la metabolización del alcohol podría ser el responsable de los efectos de la resaca. También parece que los efectos están relacionados con la disrregulación de la Cytokina modificada por los niveles elevados de Tromboxano B2 durante la inducción experimental de resaca por alcohol.

Se han observado alteraciones hormonales en pacientes con resaca. La gravedad es proporcional a la concentración de Hormona Antidiurética que es inhibida en riñón por los efectos del alcohol induciendo diuresis $y$ deshidratación. También están incrementados los niveles séricos de aldosterona y renina pero no se correlacionan bien con la severidad de la resaca. En relación al metabolismo de la glucosa se sabe que el Glucagón está incrementado en la IEA pero sus efectos sobre la resaca son desconocidos. El Cortisol libre está disminuido durante la IEA pero no durante la resaca mientras que las hormonas tiroideas y la hormona de crecimiento no sufren cambios en la IEA ni en la resaca, en cambio en ambos casos se produce acidosis metabólica ${ }^{35}$.

Los cambios hemodinámicos observados en la resaca son alteraciones en la presión sanguínea y en la medida de la fracción de eyección de la salida ventricular. No se ha observado vasodilatación periférica que sí aparece en la IEA por lo que en la resaca está aumentado el trabajo cardíaco pero con resistencias periféricas normales lo que explica la asociación de la resaca al aumento de la mortalidad cardíaca observada. Asimismo los pacientes con resaca tienen un trazado electroencefalográfico lento que persiste durante más de 16 horas después de que los niveles de alcohol en sangre son indetectables. Aparece disminución de la respuesta en los potenciales evocados y déficits psicomotores por lo que la resaca cursa con síntomas de depresión cortical difusa a diferencia del S.A.A. que cursa con manifestaciones de hiperexcitabilidad cerebral ${ }^{35}$.
Tratamiento de la resaca: La falta de instrumentos estandarizados dificulta la comparación de los tratamientos. En pacientes con resacas ocasionales se recomienda adecuada hidratación e información de los efectos al paciente. La terapia sintomática mejora los síntomas pero persisten los trastornos visuoespaciales, cognitivos y cardiovasculares. El propanolol no mejora los síntomas de la resaca y la administración de glucosa o fructosa tampoco.

El Acido Tolfelánico inhibidor de las Prostaglandinas, administrado profilácticamente cuando la persona va a beber alcohol, mejora los síntomas de la resaca presentando menor cefalea, naúseas, vómitos, irritación y tristeza.

La administración profiláctica de Vitamina B6 reduce los síntomas de la resaca en un $50 \%$ por mecanismo aún desconocido; el Clormetiazol también reduce los síntomas pero disminuye el funcionamiento cognitivo y tiene efectos secundarios importantes como la sedación ${ }^{35}$.

\section{CONCLUSIONES}

El etanol a diferencia de otras sustancias adictivas es un importante tóxico celular que produce alteraciones multiorgánicas y daños irreversibles orgánicos con elevada morbimortalidad. La toxicidad es mayor en el sexo femenino.

Desde hace tres décadas se considera al Acetaldehido originado por el sistema activo de catalasa cerebral el responsable de algunos efectos psicofarmacológicos y neurotóxicos del etanol. Asímismo el Acetaldehido podría ser el responsable de los síntomas de la resaca.

El etanol no tiene receptor específico pero la administración aguda de elevadas cantidades potencian los receptores excitatorios como el Nicotínico colinérgico y el 5-HT3 serotoninérgico produciendo activación; potencia el receptor excitatorio NMDA glutamatérgico produciendo sedación y activa el 
sistema dopaminérgico mesolímbico produciendo efecto reforzador positivo.

Dentro de una amplia variabilidad individual, en la IEA típica existe una clara relación entre la concentración de etanol en sangre y el perfil de los efectos farmacológicos, no así en las embriagueces atípicas. Tras el desarrollo de neuroadaptación y tolerancia por el consumo crónico de alcohol disminuyen los efectos de la IEA y es menos frecuente la resaca.

Los hijos de alcohólicos presentan menor sensación subjetiva de intoxicación alcohólica y mayor frecuencia de resaca, siendo ambos factores predictores de mayor riesgo de Alcoholismo.

La IEA y la resaca son síndromes con importancia que requieren abordajes específicos. Hay que prestar especial atención a los pacientes con alcoholemias elevadas o riesgo evidente de coma etílico, a los pacientes con Dependencia de Alcohol por posible S.A.A., a los pacientes con embriagueces atípicas, con resaca afectos de alteraciones coronarias y cardiacas, con policonsumos porque presentan intoxicaciones más graves, de más difícil manejo y mayor riesgo de síndromes de abstinencia y a los pacientes con crisis convulsivas y tentativas de suicidio.

Ante toda IEA descartar la presencia de otras drogas asociadas, especialmente en los intentos autolíticos.

\section{BIBLIOGRAFÍA}

(1) Rodríguez-Martos A, Manual de Alcoholismo para el médico de cabecera.Barcelona:Salvat Editores; 1989. P. 93-97.

(2) Keller M, Termes employes en alcoologie. En: Edwards G, y cols. Eds.Incapacités liées à la consommation d'alcool.Ginebra: OMS, Offset publication; $1977, \mathrm{n}^{\circ} 32$.

(3) * Guerola J, Martínez C, Urgencias médicas originadas por consumo de alcohol. En:Cuevas J, Sanchís M, editores. Tratado de Alcohología. Nilo; 2000. P. 305-317.
(4) Portella E, Ridao M, Carrillo E et al, El alcohol y su abuso. Impacto Socioeconómico. Madrid: Panamericana; 1988.

(5) World Drink Trends, Produktschap woor gedistilleerde dranken /NTC Pub Ltd. Henley-Thames; 1.996.

(6) Gil E, Robledo T, Rubio J, Medio Ambiente y Estilos de vida: Tabaco y Alcohol. Comunicación a Jornadas de cooperación Sanitaria. Madrid; 1.998.

(7) Delegación del Gobierno para el Plan Nacional sobre Drogas (DGPNSD) Observatorio Español, Plan Nacional sobre Drogas. Encuesta domiciliaria sobre consumo de drogas, 1997. Informe 1. Madrid; 1999.

(8) ** Guardia J. Neurobiología del Alcohólismo. En: Rubio G, Santo-Domingo J, Coordinadores.Curso de Especialización en Alcoholismo. Madrid: Fundación de Ayuda contra la Drogadición; 2001. Capítulo 3.

(9) * * Guerri C,Cómo actúa el alcohol en nuestro cerebro. Trastornos Adictivos; 2000. 2 (1): 1425.

(10) * Alamo C, López-Muñoz B, Martín E, Cuenca E. Farmacología del Etanol. En: Rubio G, SantoDomingo J, Editores.Guía Práctica de Intervención en el Alcoholismo. Nilo; 2000. P. 85-113.

(11) Velasco A, Alvarez FJ, Alcoholes Alifáticos. En: Velasco A, Alvarez FJ, Editores. Compendio de Psiconeurofarcología. Madrid : Díaz de Santos; 1988. P. 285-293.

(12) Fox AW, Guzmán NJ, Friedman PA, The Clinical Pharmacology of Alcohol. In:Barnes HN, Aronson MD, Delbanco TL,Eds. Alcoholism: a guide for the primary care physician. New York: Springer Verlag; 1987. P. 29-43.

(13) Alguacil LF, Aspectos farmacológicos del Alcoholismo. En : Valvuena A, Alamo C, Editores. Avaances en Toxicomanías y Alcoholismo.Alcalá de Henares : Servicio de Publicaciones Universidad de Alcalá;1996. P. 31-38.

(14) Goldstein DB, Effects of Alcohol on Membrane Lipids. In: Begleiter H, Kissin B, Eds. The Pharmacology of Alcohol and Alcohol Dependence. New York :Oxford University Press; 1996. P. 309-334.

(15) Tabakoff B, Hoffman PL, Neurobiology of Alcohol.In: Galanter \& Kleber, Eds Texbook of Substance abuse Treatment Second Edition.Tthe American Psiquiatric Press; 1999. P. 3-10. 
(16) * Rubio G, Santo-Domingo J, Urgencias Relacionadas con el Consumo de Alcohol. En: Rubio G, Santo-Domingo J, Guía Práctica de Intervención en Alcoholismo. Nilo; 2000. P. 175-189.

(17) Schuckit MA, Smith TI, An 8- year followp of 450 sons of alcoholic and control subjects. Arch. Gen. Psychiatry; 1.996. 53: 202-210.

(18) Hales E, Yudofsky C, Talbott A. The Americam Psyquiatric Press. Tratado de Psiquiatría. $3^{a}$ Edición. Barcelona: Masson ;2000. P. 370-371.

(19) Minian E, Slorid M, Bontiette L, Severe alcohol intoxication: a study of 204 consecutive patients Clinical Toxicology; 1989, 27, 375-384.

(20) Soler Insa Pa, Freixa F, Reina F, Trstorno por Dependencia de Alcohol. Madrid: Gráficas Cristal; 1988.

(21) American Psychiatria Association (APA).Manual Diagnóstico y Estadístico de los Trastornos Mentales (DSM-IV); Barcelona : Masson; 1997.

(22) Glass IB, The international handbook of addiction behaviour. London.Routledge: Edited by Glass IB; 1.991.

(23) Organización Mundial de la Salud ( OMS).Descripciones Clínicas y Pautas para el Diagnóstico de Trastornos Meentales y del Compotamiento ( CIE 10 ); 1992.

(24) Kaplan H, Sadock J, Grebb A, Sinopsis de Psiquiatría. $7^{a}$ ed...Madrid: Editorial Médica Panamericana; 1996. P. 410.

(25) Organización Mundial de la Salud, Evaluación de los problemas sociales y de salud pública relacionados con el uso de sustancias psicotropas. Serie de Informes técnicos N 656; Ginebra: OMS;1981.
(26) Brismar B, Engstom A, Rydberg U, Head injury and intoxication: a diagnostic and therapeutic problem; Acta Chir Scand; 1983. 149: 11-14.

(27) Janicak PG, Piszczor J, Alcohol-related syndrome. In:Flaberty JA, Channon RA, Davis 3M, Psychiatry: Diagnosis and therapy. East Norwalk:Appleton and Lange; 1988. P. 166-181.

(28) * Hyman E,Manual de Urgencias Psiquiátricas. $1^{\text {a }}$ ed. Barcelona: Salvat Editores; 1987. P. 185195.

(29) Sáez A, Martínez F, Martínez JM et al, Urgencias en Drogodependencias:Pautas de Actuación en Atención Primaria de Salud. Revista de Salud Pública de Castilla y León; 1987. Vol 1, 25-27.

(30) Alvarez S, de Lucas MT, Santo Domingo J, Transtornos Mentales y del Comportamiento debido al Consumo de Sustanacias Psicotropas.En: http:// www. Intersep.org/ manual/ a 8n2.htm.;1.988.

(31) Montero FJ, Sánchez C, Clemente V et al,Intoxicaciones Agudas II. En:Jiménez L, Montero FJ, Protocolos de Actuación en Medicina de Urgencias. Ed. Harcourt Brace; 1996. 30: 204-205.

(32) Murphy GF,Suicide in alcoholism. Neuw York: Oxford University Press Inc; 1992.

(33) * Sociedad Española de Psiquiatría.Diagnóstico y Tratamiento del Alcoholismo y otras Drogodependencias. Madrid: Aula Médica; 2000. P. 127-170.

(34) * Azanza JR, . Guía Práctica de Farmacología del Sistema Nervioso Central. 2a Edición. Madrid: Ediciones; 1999.

(35) ** Wiese JG,Shlipak MG,Brower WS, The alcohol hangover. Ann Intern Med; 2000. 132(11): 897-902. 